\title{
Metabolic Control in Children and Adolescents with Insulin-Dependent Diabetes Mellitus at King Abdul-Aziz University Hospital
}

\author{
Abdulmoein Al-Agha, Ali Ocheltree, Amr Hakeem \\ King Abdulaziz University, Department of Pediatrics, Jeddah, Saudi Arabia
}

\section{ABSTRACT}

Objective:Preventing long-term diabetic complications requires good metabolic control, especially in type 1 diabetes mellitus (T1DM). We describe the metabolic control of T1DM and the factors affecting it among children and adolescents attending the Pediatric Clinic at King Abdul-Aziz University Hospital.

Methods: A retrospective cross-sectional study was conducted on T1DM children and adolescents who had attended the Pediatric Clinic at King Abdul-Aziz University Hospital from 2006 to 2010. Both clinical and laboratory data were reviewed for the enrolled cases. The mean age of the patients was $12.5 \pm 4.1$ years. Ages ranged from 1 to 18 years $(n=484$ : male $=213$, female $=271$ ). $38.6 \%$ of the patients were pre-pubertal and $61.4 \%$ - pubertal. The patients were categorized into 3 age groups as 1-6 years $(10.3 \%)$, $7-12$ years $(33.5 \%)$ and $13-18$ years $(56.2 \%)$.

Results: The overall mean $\mathrm{HbA1c}$ was $9.4 \pm 2.4 \%$ and the duration of patient follow-up was $26 \pm 17$ months. $10.3 \%$ of the patients were on conventional insulin regimens and $89.7 \%$ - on intensive insulin therapy.

$31.4 \%$ had satisfactory $\mathrm{HbA1C}$ according to the American Diabetes Association guidelines. The duration of T1DM was $2.9 \pm 1.4$ years. The patients with diabetes duration $\leq 2$ years $(45 \%)$ had a mean $\mathrm{HbA} 1 \mathrm{c}$ of $8.7 \pm 1.8 \%$ and those with diabetes duration $>2$ years $(55 \%)$ had a mean $\mathrm{HbA} 1 \mathrm{c}$ value of $9.8 \pm 2.3 \%(\mathrm{p}<0.001)$.

Conclusions: The metabolic control of T1DM children in our cohort was less satisfactory than in other studies. We recommend the promotion of physical exercise and family educational programs to improve the metabolic control of T1DM pediatric patients in our population.

Key words: Metabolic control, insulin-dependent diabetes mellitus, HbA1c, children, adolescents

Conflict of interest: None declared

Received: 19.06.2011

Accepted: 04.10.2011

\section{Introduction}

Type 1 diabetes mellitus (T1DM) is a common chronic disease in childhood. Fifty percent of subjects with T1DM are diagnosed within the first 15 years of life (1). The Diabetes Control and Complications Trial and the Epidemiology of Diabetes Interventions and Complications study demonstrated that improving metabolic control in children and adolescents with T1DM reduced the risk of diabetic complications $(2,3)$. Previous studies have attributed poor metabolic control among adolescents to their changing physiology (pubertal growth and development) as well as to behavioral and adherence issues $(4,5,6)$. Intensified insulin therapy resulted in a better metabolic control and reduced diabetic complications (7). Good metabolic control is crucial for the prevention of long-term diabetic complications (8). This can be achieved by daily self-monitoring of blood glucose (SMBG), multiple daily insulin injections, regular $\mathrm{HbA1c}$ measurements, and attention to physical activity. Exercise is an essential component in blood glucose regulation for T1DM patients, along with insulin management (9). The American Diabetes Association (ADA) emphasized the importance of ongoing education in prevention of and screening for diabetes complications (10). Diabetes education programs have small to medium beneficial effects on metabolic control $(11,12)$

Address for Correspondence

Abdulmoein Al-Agha MD, King Abdulaziz University, Department of Pediatrics, Jeddah 21589, Saudi Arabia

Phone: +966 505590459 Fax: +966 26408306 E-mail: aagha@kau.edu.sa

(c) Journal of Clinical Research in Pediatric Endocrinology, Published by Galenos Publishing. 
and somewhat greater effect on psychological outcomes (13). We describe the current level of metabolic control in children and adolescents attending the pediatric endocrine clinic at King Abdul-Aziz University (KAAU) Hospital and the impact of different factors such as age, pubertal stage, gender, duration of diabetes, insulin regimen, family diabetes education, and physical exercise on the metabolic control of T1DM pediatric patients in our population.

\section{Methodology}

\section{Study Design and Subjects}

This retrospective cross-sectional study was conducted on all children and adolescents who had attended the pediatric endocrine clinic at KAAU Hospital from 2006 to 2010. Inclusion criteria were: follow-up period in the pediatric endocrine clinic for more than 3 months, patient age between 1 and 18 years, and an $\mathrm{HbA} 1 \mathrm{c}$ value $>6.5 \%$. A total of 547 patients were retrospectively reviewed and 63 were excluded from the study due to age (becoming $\geq 18$ years during the study period) or to a follow-up period of less than 3 months. Thus, the study population consisted of 484 children and adolescents with T1DM, aged from 1 to 18 years. Mean, standard deviation (SD) and median for age values were $12.5 \pm 4.1$ and 13 years, respectively. The mean $( \pm S D)$ follow-up period was $26 \pm 17$ months (range: 8-48 months). A total of $72(15 \%)$ patients were followed up for 4 years. Of the study population, 213 were males (44\%) and 271 were females (56\%); 187 were pre-pubertal (38.6\%) and 297 were pubertal $(61.4 \%)$.

Duration of T1DM, attendance to diabetes education sessions and seminars, insulin regimen, rate of $\mathrm{SMBG}$, Tanner staging, regularity of physical exercise, and serum $\mathrm{HbA} 1 \mathrm{c}$ were reviewed from patient clinical and laboratory records. We categorized all patients into three age groups: toddlers and pre-school children (1-6 years), 50/484 (10.3\%); school children (7-12 years), 162/484 (33.5\%); and adolescents and young adults (13-18 years), 272/484 (56.2\%). Prior to data entry into the study database for analysis, all collected variables were reviewed by a pediatric endocrinology consultant at KAAU for data quality assurance. In the present study, we followed the ADA guidelines for target $\mathrm{HbA} 1 \mathrm{c}$ levels per age group. The ADA recommends a target $\mathrm{HbA} 1 \mathrm{c}$ of approximately $8.5 \%$ in toddlers, between $7.5 \%$ and $8.5 \%$ in pre-school children, $\leq 8 \%$ in school children, and $\leq 7.5 \%$ in adolescents and young adults (10). In contrast, the more stringent guidelines of the International Society for Pediatric and Adolescent Diabetes recommend that a target $\mathrm{HbA} 1 \mathrm{c}$ level of $<7.5 \%$ should be achieved without succumbing into episodes of severe hypoglycemia (14).

\section{Insulin Regimens and SMGB}

The protocol used in the pediatric endocrine clinic at KAAU regarding insulin regimens for T1DM children and adolescents is conventional insulin regimen for both toddlers and pre-school children and intensive insulin regimen for children $>6$ years and all adolescents. Conventional insulin regimen was defined as the administration of 2 injections of insulin/day as a combination of regular short-acting and intermediate-acting insulin before breakfast and dinner, coupled with SMBG and adjustments of insulin dosage in response to the individual's metabolic control. Importantly, hyperglycemia (depending on age) was corrected with short- or rapid-acting insulin. Intensive insulin regimen was defined as either receiving 3 insulin injections/day, and in addition receiving a basal bolus of insulin, or being on an insulin pump. Insulin basal bolus was defined as a rapidor short-acting insulin injection before each meal and either a single long-acting basal dose or two intermediate-acting doses to cover the basal need for insulin between meals and during the night. Patient rate of SMBG was reviewed from the clinical records. Values of $\mathrm{HbA1c}$ were based on measurement at regular intervals ( 3 months) and then averaged to create a 4-year mean exposure variable for each enrolled subject. At KAAU, HbA1c is measured by the SEIMENS Dimension clinical chemistry system using a GLU Flex reagent cartridge. The laboratory test is the hexokinase method.

\section{Diabetes Education and Physical Exercise}

Patient compliance to physical exercise and diabetes education sessions, as well as the weekly frequency of physical exercise, was assessed from a review of the hospital records of the enrolled subjects. The patients were divided into 3 categories with respect to physical exercise: the first group did not indulge in physical exercise; the second group performed physical exercise 1-2 times/week; and the third group performed physical exercise 3-4 times/week. Compliance to physical exercise was defined as continuous physical exercise lasting $\geq 30$ minutes/day both indoors and outdoors. Compliance to diabetes education events was defined as attendance of $\geq 1$ session, symposium, seminar, lecture, and clinical appointment/month.

\section{Statistical Analysis}

The data were compiled from KAAU Hospital phoenix database. SPSS version 16.0 software was used for the analysis. Continuous variables were represented as mean $( \pm S D)$ and categorical variables as percentages. Student t-test, Mann-Whitney $U$ test, and Kruskal-Wallis test were used for comparative evaluation. When appropriate, Chi-square test and cross tabulations were applied for the analysis of categorical data. Spearman's rank correlation coefficient was used to study the correlation between $\mathrm{HbA} 1 \mathrm{c}$ and age. A p-value of $<0.05$ was taken as 
statistically significant for individual variables. As this was primarily a study of the entire population of T1DM pediatric patients who had attended the pediatric endocrine clinic at KAAU Hospital, sample size calculations were not performed a priori. This study was approved by the biomedical ethics department at KAAU, Faculty of Medicine.

\section{Results}

Metabolic control became more challenging as pediatric patients advanced in age. Gender did not influence the metabolic control in our cohort (Table 1). The overall HbA1c was $9.4 \pm 2.4$ and $8.8 \%$ (mean \pm SD and median, respectively). Metabolic control was less satisfactory in the pubertal group compared to the pre-pubertal group ( $\mathrm{HbA} 1 \mathrm{c} 10 \pm 2.6 \mathrm{vs}$. $8.5 \pm 1.7 \%, p<0.001)$. Of a total of 484 patients, $152(31.4 \%)$ had satisfactory $\mathrm{HbA} 1 \mathrm{c}$ values according to the ADA guidelines. In our cohort, 50/484 were on conventional insulin regimens (10.3\%) and 434/484 were on intensive insulin therapy (89.7\%); only $18 / 434(4.1 \%)$ of those on intensive insulin therapy had an insulin pump. Metabolic control among the toddlers and pre-school age group was more satisfactory when compared to the school and adolescent age groups (Table 2). A positive correlation was found between $\mathrm{HbA} 1 \mathrm{c}$ and age $(r=+0.3, \mathrm{p}<0.001)$. In our cohort, $138 / 484$ patients $(28.51 \%$ ) were compliant to diabetes education programs. $\mathrm{HbA} 1 \mathrm{c}$ levels were $8.2 \pm 0.5$ for

\begin{tabular}{|c|c|c|c|}
\hline & $\begin{array}{l}\text { Well controlled } \\
(n=152)\end{array}$ & $\begin{array}{l}\text { Poorly controlled } \\
\quad(n=332)\end{array}$ & $p$ value \\
\hline Age (years) & $10.3 \pm 4.1$ & $13.4 \pm 3.6$ & $<0.001^{\dagger}$ \\
\hline Gender (female) & $89(58.6)$ & $182(54.8)$ & NS \\
\hline $\mathrm{HbA1c}(\%)$ & $7.2 \pm 0.5$ & $10.4 \pm 2.3$ & $<0.001^{\dagger}$ \\
\hline Duration of T1DM (years) & $2.4 \pm 1.2$ & $3 \pm 1.3$ & $<0.05^{*}$ \\
\hline $\begin{array}{l}\text { Insulin regimen } \\
\text { (intensive insulin therapy) }\end{array}$ & $120(79)$ & $314(94.6)$ & $<0.05^{*}$ \\
\hline $\begin{array}{l}\text { Compliance to } \\
\text { educational activities }\end{array}$ & $128(84.2)$ & $10(3)$ & $<0.001^{\dagger}$ \\
\hline SMBG $\geq 4$ times/day & $102(67.1)$ & $85(25.6)$ & $<0.05^{*}$ \\
\hline No physical exercise & $61(40.1)$ & $264(79.5)$ & $<0.001^{\dagger}$ \\
\hline Exercise (1 to 2/week) & 67 (44.1) & 57 (17.2) & $<0.001^{\dagger}$ \\
\hline Exercise (3 to 4/week) & $24(15.8)$ & $11(3.3)$ & $<0.001^{\dagger}$ \\
\hline
\end{tabular}

those who were compliant to diabetes education programs and $10 \pm 1.9$ for those who were not compliant. The difference between these two groups was significant $(p<0.05)$. Of a total of $484,187(38.6 \%)$ patients were compliant with SMBG $\geq 4$ times/day; 119 of the 187 (63.6\%) subjects were also compliant to the diabetes education exercises. The mean duration of T1DM was $2.9 \pm 1.4$ years. In 218 of the 484 patients $(45 \%)$, diabetes duration was $\leq 2$ years and the mean $\mathrm{HbA} 1 \mathrm{c}$ value was $8.7 \pm 1.8 \%$ In 266 $(55 \%)$, diabetes duration was $>2$ years (mean $\mathrm{HbA} 1 \mathrm{c} 9.8$ $\pm 2.3 \%$ ). The difference between $\mathrm{HbA} 1 \mathrm{c}$ values was significant $(p<0.001)$. The duration of T1DM was $2.5 \pm 1.1$ years in those with controlled HbA1c (according to the ADA guidelines) and $3 \pm 1.2$ years in those with uncontrolled $\mathrm{HbA} 1 \mathrm{c}$. The difference was significant $(\mathrm{p}<0.05)$. According to the clinical records, only 35 of the 484 enrolled children (7.2\%) performed regular physical exercise 3 to 4 times a week, $124(25.6 \%)$ exercised 1 to 2 times a week, and the majority 325 (67.2\%) did not perform any physical exercise on a regular basis. The mean $\mathrm{HbA} 1 \mathrm{c}$ levels in these groups were $7.1 \pm 0.6,8.2 \pm 0.7$, and $10.3 \pm 2.7$, respectively, with a $p$ value of $<0.001$ (Kruskal-Wallis test).

\section{Discussion}

Several studies have reported on the metabolic control of T1DM children and adolescents $(15,16,17,18)$, but this is the first to examine the metabolic control among T1DM pediatric patients in Saudi Arabia and has relevance to the planning and improvement of care in developed and less well-developed settings serving children and adolescents with T1DM. Specifically, this study demonstrates that attention to both physical exercise and diabetes education programs can be effectively established and that they are

\begin{tabular}{|c|c|c|c|}
\hline Age group & $\begin{array}{l}\text { Number (\%) } \\
\text { of patients }\end{array}$ & HbA1c & $\begin{array}{c}\text { Number (\%) } \\
\text { of patients } \\
\text { with good } \\
\text { metabolic control* }\end{array}$ \\
\hline $\begin{array}{l}\text { Toddlers and pre- } \\
\text { school children } \\
\text { (1 to } 6 \text { years) }\end{array}$ & $50(10.3)$ & $8.4 \pm 1.5$ & 32 (64) \\
\hline $\begin{array}{l}\text { School children } \\
\text { (7 to } 12 \text { years) }\end{array}$ & $162(33.5)$ & $8.8 \pm 1.9$ & 75 (46.3) \\
\hline $\begin{array}{l}\text { Adolescents and } \\
\text { young adults } \\
\text { (13 to } 18 \text { years) }\end{array}$ & $272(56.2)$ & $10 \pm 2.7$ & $45(16.5)$ \\
\hline \multicolumn{4}{|c|}{$\begin{array}{l}\text { Values are given as numbers of patients and percentages }(\%) \text { or as mean } \pm \text { SD. } \\
\text { *According to the ADA guidelines for target } \mathrm{HbA1c} \text { in T1DM pediatric patients. } \\
\text { T1DM: type } 1 \text { diabetes mellitus, HbA1c: hemoglobin A1c, ADA: the American } \\
\text { Diabetes Association }\end{array}$} \\
\hline
\end{tabular}


associated with improved clinical outcomes. Furthermore, despite the fact that several confounding factors play a role in metabolic control, this study shows that conventional insulin therapy may still be an appropriate therapeutic option in managing young children ( $\leq 6$ years) with T1DM.

Good metabolic control in T1DM pediatric patients reduces the incidence of complications and delays the progression of existing complications (19). It is also essential for normal growth and development (20). In our cohort, insulin regimens were not the only factor influencing metabolic control of T1DM pediatric patients. Lack of physical exercise, negligence to adhere to daily SMBG and to diabetes education programs were other contributing factors. Prevalence of T1DM among children and adolescents in Saudi Arabia was found to be 109.5/100 000 and this country has the lowest reported prevalence rate compared to some other countries in children $<6$ years of age (21). This might explain why few patients in our cohort were younger than 6 years of age.

Intensive insulin therapy is the method of choice in managing T1DM pediatric patients $(7,22)$. Paradoxically, there was a higher percentage of subjects receiving intensive insulin therapy in the poor control group. The reason for this is that the majority of our cohort $(89.7 \%)$ was on intensive insulin therapy, which precludes precise comparisons between conventionally and intensively treated patients. Furthermore, the KAAU endocrine pediatric clinic prefers to start children on intensive insulin therapy as early as possible (around the age of 7 years) in order to improve their metabolic control and reduce the risk of diabetic complications. Initiation of such therapy in young children ( $\leq 6$ years) is limited by problems related to non-acceptance of multiple injections due to fear of needles, fear of both the child and his/her parents of severe hypoglycemic attacks, especially in those who have had a past history of seizures during their sleep, unpredictability of a toddler's dietary intake and activity level, difficulty of adherence to daily $S M B G$ and regular measurements of $\mathrm{HbA1c}$, and lack of regular exercise. Subcutaneous insulin infusion therapy may provide yet another solution for some patients, but without government subsidy, this type of treatment is not affordable for most families (23). Indeed, very few families in our cohort $(4.1 \%)$ could afford insulin pump therapy.

Several studies reported that metabolic control was worse in adolescents compared to younger children $(16,24)$. In our cohort, younger children had a better control compared to adolescents. Interestingly, T1DM patients $\leq 6$ years of age who were on conventional insulin therapy had good metabolic control. Intensive insulin therapy is the preferred therapeutic approach in managing children and adolescents with T1DM $(7,22)$. However, conventional insulin regimens consisting of two insulin injections daily may still be an appropriate therapeutic option for children $\leq 6$ years of age, particularly for families who cannot afford intensive insulin therapy. This choice has to be made together with the patient and his/her parents upon consideration of several factors such as: age; acceptance of a restricted versus flexible diet; acceptance of a fixed versus flexible but multiple insulin injections between snacks and meals; the cultural and intellectual background of the subject and of the family; compliance; and a history of a partial remission phase. Both Tonella et al (16) and Dorchy et al (17) reported that no significant difference was observed between $\mathrm{HbA} 1 \mathrm{c}$ levels of conventionally versus intensively treated patients. Nonetheless, it has been shown that intensive insulin treatment may result in a better metabolic control and cause less complications when compared with conventional approaches $(25,26)$. However, compliance to intensive regimens has been shown to be weaker than compliance to conventional regimens, suggesting a mismatch between the treatment regimen proposed by the clinician and the extent to which patients and their families can manage diabetes (27).

Several studies conducted on children and adolescents with T1DM have demonstrated that both patient and family education were associated with a reduction in number of hospitalizations, emergency room visits, and a reduction in overall healthcare expenses $(28,29)$. Diabetes education is not a one-time event that occurs at diagnosis. Indeed, many studies have shown that to be effective, educational interventions need to be both continuous and regular. Only then can these efforts lead to improved $\mathrm{HbA} 1 \mathrm{c}$ values and decreased hospitalization rates $(15,27,28,29,30)$. The ADA recommends that T1DM children and adolescents, especially those who are highly active, should monitor their blood glucose levels $\geq 4$ times/day, (10). In the present study, families compliant to diabetes education events appreciated the value of SMBG and were able to manage their children's T1DM with greater success. Specialized pediatric dietitians can give more appealing advice to children and this will ultimately improve their overall adherence to a T1DM-suitable lifestyle (15).

The ADA, Center for Disease Control and the American College of Sports Medicine all recommend that children and adolescents with T1DM should have a minimum of 30 to 60 minutes of exercise/day (10). In our cohort also, patients with T1DM who exercised regularly, enjoyed a better metabolic control. Michaliszyn et al. have reported that greater fitness levels predicted better metabolic control in adolescents with T1DM (18). Benefits of physical exercise in T1DM children and adolescents include 
satisfactory metabolic control, greater sense of well-being, weight control, improved physical fitness, improved cardiovascular fitness with lower pulse, lower blood pressure, and improved lipid profile $(10,31)$. Herbst et al demonstrated that the frequency of regular physical activity was associated with lower $\mathrm{HbA} 1 \mathrm{c}$ levels, but interestingly, without increasing the risk of severe hypoglycemia (32). Nonetheless, $10-20 \%$ of hypoglycemic episodes are associated with exercise, thus, frequent blood glucose monitoring is imperative (10).

The duration of T1DM and also the age of the patient affected the metabolic control of children and adolescents with T1DM in our cohort. Those with a $<2$ years duration of diabetes had lower HbA1c levels compared to those who had longer diabetes duration. Flück et al (24) reported that metabolic control was worse in pubertal adolescents compared to pre-pubertal children and also reported that patients with a duration of diabetes $<2$ years had better metabolic control than those with a longer duration. In our cohort, gender did not affect the metabolic control of children and adolescents with T1DM, in contrast to findings reported in several studies $(17,24)$. Among those on intensive insulin therapy in our cohort, good metabolic control was achieved in $46.3 \%$ of the patients who were younger than 13 years, while only $16.5 \%$ of those who were older than 13 years had a good metabolic control.

Our study had some limitations. Firstly, the unequal distribution of patients among age groups in our population precludes precise comparisons. Secondly, in this retrospective study, we were not able to assess either the rates of hypoglycemia, a parameter which is important particularly for T1DM patients on intensive insulin therapy, or the nutritional/dietary status and life style of the patients, except for their practice of physical exercise.

From the results of this study, we conclude that the best therapeutic approach in pediatric patients with T1DM is intensive insulin therapy. However, other factors such as duration of diabetes, attendance to both diabetic education programs and physical exercise sessions also affect metabolic control in children and adolescents with T1DM. Emphasis must be made on the importance of diabetes education in helping families improve their children's metabolic control.

\section{References}

1. Vandewalle CL, Coeckelberghs MI, De Leeuw IH, Du Caju MV, Schuit FC, Pipeleers DG, Gorus FK. Epidemiology, clinical aspects, and biology of IDDM patients under age 40 years. Comparison of data from Antwerp with complete ascertainment with data from Belgium with $40 \%$ ascertainment. The Belgian Diabetes Registry. Diabetes Care 1997;20:1556-1561.
2. The Diabetes Control and Complications Trial Research Group. The effect of intensive treatment of diabetes on the development and progression of long-term complications in insulin-dependent diabetes mellitus. $\mathrm{N}$ Engl $\mathrm{J}$ Med 1993:329:977-986.

3. Diabetes Control and Complications Trial Research Group. Effect of intensive diabetes treatment on the development and progression of long-term complications in adolescents with insulin-dependent diabetes mellitus: Diabetes Control and Complications Trial. J Pediatr 1994;125:177-188.

4. Amiel SA, Sherwin RS, Simonson DC, Lauritano AA, Tamborlane W. Impaired insulin action in puberty: a contributing factor to poor glycemic control in adolescents with diabetes. N Engl J Med 1986;315:215-219.

5. Rydall AC, Robin GM, Olmsted MP, Devenyi RG, Daneman D. Disordered eating behavior and microvascular complications in young women with insulin-dependent diabetes mellitus. N Engl J Med 1997:336:1849-1854.

6. Wysocki Y, Taylor A, Hough BS, Linscheid TR, Yeates KO, Naglieri JA. Deviation from developmentally appropriate self-care autonomy. Diabetes Care 1996;19:119-125.

7. Nathan DM, Cleary PA, Backlund JY, Genuth SM, Lachin JM, Orchard TJ, Raskin P, Zinman B; Diabetes Control and Complications Trial/Epidemiology of Diabetes Interventions and Complications (DCCT/EDIC) Study Research Group. Intensive diabetes treatment and cardiovascular disease in patients with type 1 diabetes. $N$ Engl J Med 2005;353:2643-2653.

8. Nordwall M, Arnqvist HJ, Bojestig M, Ludvigsson J. Good glycemic control remains crucial in prevention of late diabetic complications--the Linköping Diabetes Complications Study. Pediatr Diabetes 2009;10:168-176.

9. Robertson K, Adolfsson P, Scheiner G, Hanas R, Riddell $\mathrm{MC}$. Exercise in children and adolescents with diabetes. Pediatr Diabetes 2009;10:154-168.

10. Silverstein J, Klingensmith G, Copeland K, Plotnick L, Kaufman F, Laffel L, Deeb L, Grey M, Anderson B, Holzmeister LA, Clark N; American Diabetes Association. Care of children and adolescents with type 1 diabetes: a statement of the American Diabetes Association. Diabetes Care 2005;28:186-212.

11. Murphy HR, Rayman G, Skinner TC. Psycho-educational interventions for children and young people with Type 1 diabetes. Diabetic Med 2006:23:935-943.

12. Hampson SE, Skinner TC, Hart J, Storey L, Gage H, Foxcroft D, Kimber A, Shaw K, Walker J. Effects of educational and psychosocial interventions for adolescents with diabetes mellitus: a systematic review. Health Technol Assess 2001;5:1-79.

13. Winkley K, Ismail K, Landau S, Eisler I. Psychological interventions to improve glycaemic control in patients with type 1 diabetes: systematic review and meta-analysis of randomised controlled trials. BMJ 2006;333:65-65.

14. Rewers M, Pihoker C, Donaghue K, Hanas R, Swift $P$, Klingensmith GJ. ISPAD Clinical Practice Consensus Guidelines 2009 Compendium. Assessment and monitoring of glycemic control in children and adolescents with diabetes. Pediatr Diabetes 2009;10:71-81.

15. Mortensen HB, Robertson KJ, Aanstoot HJ, Danne T, Holl RW, Hougaard P, Atchison JA, Chiarelli F, Daneman D, Dinesen B, Dorchy $H$, Garandeau $P$, Greene S, Hoey H, Kaprio EA, Kocova M, Martul P, Matsuura N, Schoenle EJ, Søvik O, Swift 
PG, Tsou RM, Vanelli M, Aman J. Insulin management and metabolic control of type 1 diabetes mellitus in childhood and adolescence in 18 countries. Hvidøre Study Group on Childhood Diabetes. Diabet Med 1998;15:752-759.

16. Tonella $P$, Flück CE, Mullis PE. Metabolic control of type 1 diabetic patients followed at the University Children's Hospital in Berne: have we reached the goal? Swiss Med Wkly 2010;140:13057.

17. Dorchy H, Roggemans MP, Willems D. Glycated hemoglobin and related factors in diabetic children and adolescents under 18 years of age: a Belgian experience. Diabetes Care 1997:20:2-6.

18. Michaliszyn SF, Shaibi GQ, Quinn L, Fritschi C, Faulkner MS. Physical fitness, dietary intake, and metabolic control in adolescents with type 1 diabetes. Pediatr Diabetes 2009;10:389-394.

19. Donaghue KC, Chiarelli F, Trotta D, Allgrove J, DahlJorgensen $K$. Microvascular and macrovascular complications associated with diabetes in children and adolescents. Pediatr Diabetes 2009;10:195-203.

20. Wise JE, Kolb EL, Sauder SE. Effect of glycemic control on growth velocity in children with IDDM. Diabetes Care 1992; 15:826-830.

21. Al-Herbish AS, El-Mouzan Ml, Al-Salloum AA, Al-Qurachi MM, Al-Omar AA. Prevalence of type 1 diabetes mellitus in Saudi Arabian children and adolescents. Saudi Med J 2008;29:1285-1288

22. Mühlhauser I, Bruckner I, Berger $M$, Cheţa $D$, Jörgens $V$, Ionescu-Tîrgovişte C, Scholz V, Mincu I. Evaluation of an intensified insulin treatment and teaching programme as routine management of type 1 (insulin-dependent) diabetes. The Bucharest-Düsseldorf Study. Diabetologia 1987;30:681-690.

23. Bolli GB, Kerr D, Thomas R, Torlone E, Sola-Gazagnes A, Vitacolonna E, Selam JL, Home PD. Comparison of a multiple daily insulin injection regimen (basal once-daily glargine plus mealtime lispro) and continuous subcutaneous insulin infusion (lispro) in type 1 diabetes: a randomized open parallel multicenter study. Diabetes Care 2009;32:1170-1176.
24. Flück CE, Kuhlmann BV, Mullis PE. Metabolic control in children and adolescents with diabetes mellitus type 1 in Berne: a cross-sectional study. Schweiz Med Wochenschr 1999;129:1650-1655.

25. Chase HP, Dixon B, Pearson J, Fiallo-Scharer $R$, Walravens $P$, Klingensmith $G$, Rewers $M$, Garg SK. Reduced hypoglycemic episodes and improved glycemic control in children with type 1 diabetes using insulin glargine and neutral protamine Hagedorn insulin. J Pediatr 2003:143:737-740.

26. Murphy NP, Keane SM, Ong KK, Ford-Adams M, Edge JA, Acerini CL, Dunger DB. Randomized cross-over trial of insulin glargine plus lispro or NPH insulin plus regular human insulin in adolescents with type 1 diabetes on intensive insulin regimens. Diabetes Care 2003;26:799-804.

27. Couper JJ, Taylor J, Fotheringham MJ, Sawyer M. Failure to maintain the benefits of home-based intervention in adolescents with poorly controlled type 1 diabetes. Diabetes Care 1999;22:1933-1937.

28. Beck JK, Logan KJ, Hamm RM, Sproat SM, Musser KM, Everhart PD, McDermott HM, Copeland KC. Reimbursement for pediatric diabetes intensive case management: a model for chronic diseases? Pediatrics 2004;113:47-50.

29. Svoren BM, Butler D, Levine BS, Anderson BJ, Laffel LM. Reducing acute adverse outcomes in youths with type 1 diabetes: a randomized, controlled trial. Pediatrics 2003;112:914-922.

30. Howells L, Wilson AC, Skinner TC, Newton R, Morris AD, Greene SA. A randomized control trial of the effect of negotiated telephone support on glycaemic control in young people with Type 1 diabetes. Diabet Med 2002;19:643-648.

31. Wasserman DH, Zinman B. Exercise in individuals with IDDM. Diabetes Care 1994;17:924-937.

32. Herbst A, Bachran R, Kapellen T, Holl RW. Effects of regular physical activity on control of glycemia in pediatric patients with type 1 diabetes mellitus. Arch Pediatr Adolesc Med 2006;160:573-577. 